\title{
NEWER METHODS IN THE DIAGNOSIS AND TREATMENT OF GRANULOMA INGUINALE*
}

\author{
BY
}

\author{
ROBERT B. GREENBLATT and W. E. BARFIELD
}

From the Department of Endocrinology, Medical College of Georgia, Augusta, Ga.

Granuloma inguinale, indigenous to the South of the United States, was at one time an important problem in the area accessible to the Medical College of Georgia. The wealth of clinical material afforded ample opportunity for intensive observation of the nature of this disease for 15 years. Since the introduction of the newer antibiotics, its incidence has declined so far that our greatest problem in the past year has been to find clinical material for further studies and for teaching, The systematic eradication of this disease is one of the lesser miracles in public health.

Until recent years, little was learned about the nature of this enigmatic and recalcitrant infection, and little progress was made in therapy with the possible exception of the introduction of the antimonial compounds in 1913. The diagnostic methods and therapy here reviewed-which have eradicated this disease in our geographical area of investigation -are the result of 15 years of investigation by the Medical College of Georgia group working on the so-called minor venereal diseases. $\dagger$

\section{Diagnosis}

Biopsy.-The clinical diagnosis of an ulcerative lesion on or about the genitalia is often difficult because the chancre and condyloma of syphilis, chancroid, lymphogranuloma venereum, condyloma acuminata, and granuloma inguinale, as well as carcinoma may resemble one another or co-exist as several affections. Since specific therapy for each of these is available, the correct diagnosis is of paramount importance, and a biopsy is often warranted. Because the nature of these lesions is not readily recognized, many pathologists frequently

\footnotetext{
* Received for publication May 5, 1952. Aided by a grant from Chas. Pfizer Inc., Brooklyn, N.Y. Read at the joint meeting of the Western Branch of the American Public Health Association, San Francisco, October 29, 1951.

† In addition to the authors, the group contributing to the study includes E. R. Pund, E. S. Sanderson, R. B. Dienst, C. H. Chen, V. S. Wammock, and R. M. West.
}

render a descriptive rather than a diagnostic report, although the specific histologic picture of granuloma inguinale was described by Pund and Greenblatt $(1937 a, b)$. In histological sections the Donovan body does not stain well with the usual haematoxylin and eosin stain, but if Delafield's haematoxylin, counterstained with a small amount of eosin, is employed, the pathognomonic cell may be readily demonstrated. The relatively large size of the mononuclear cell (25 to 90 microns) and the many intracytoplasmic cysts filled with deeply stained, small, rounded bodies are its cardinal features (Fig. 1). The appearance of these bodies may vary somewhat, depending upon the depth of the spherical cyst through which the section was taken, and at times they may appear to fill the cystic spaces.

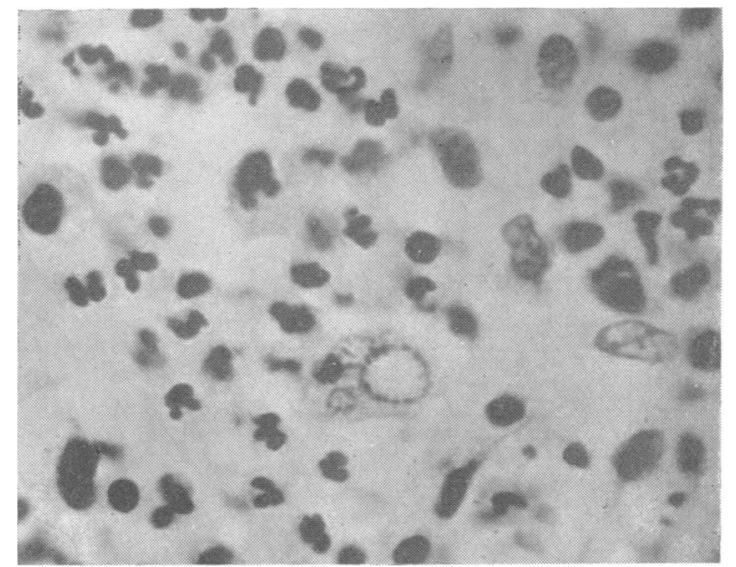

Fig. 1.-Tissue section stained with Delafield's haematoxylin and eosin. Note small rounded bodies lining periphery of intracytoplasmic cysts (from Pund and Greenblatt, 1937b).

When Dieterle's silver stain is used (as in the search for Treponema pallidum) groups of Donovan bodies may be seen in histopathological sections of granuloma inguinale because of the affinity of the capsule of the Donovan body for silver salts. These bodies reduce the silver and have a black to brown 


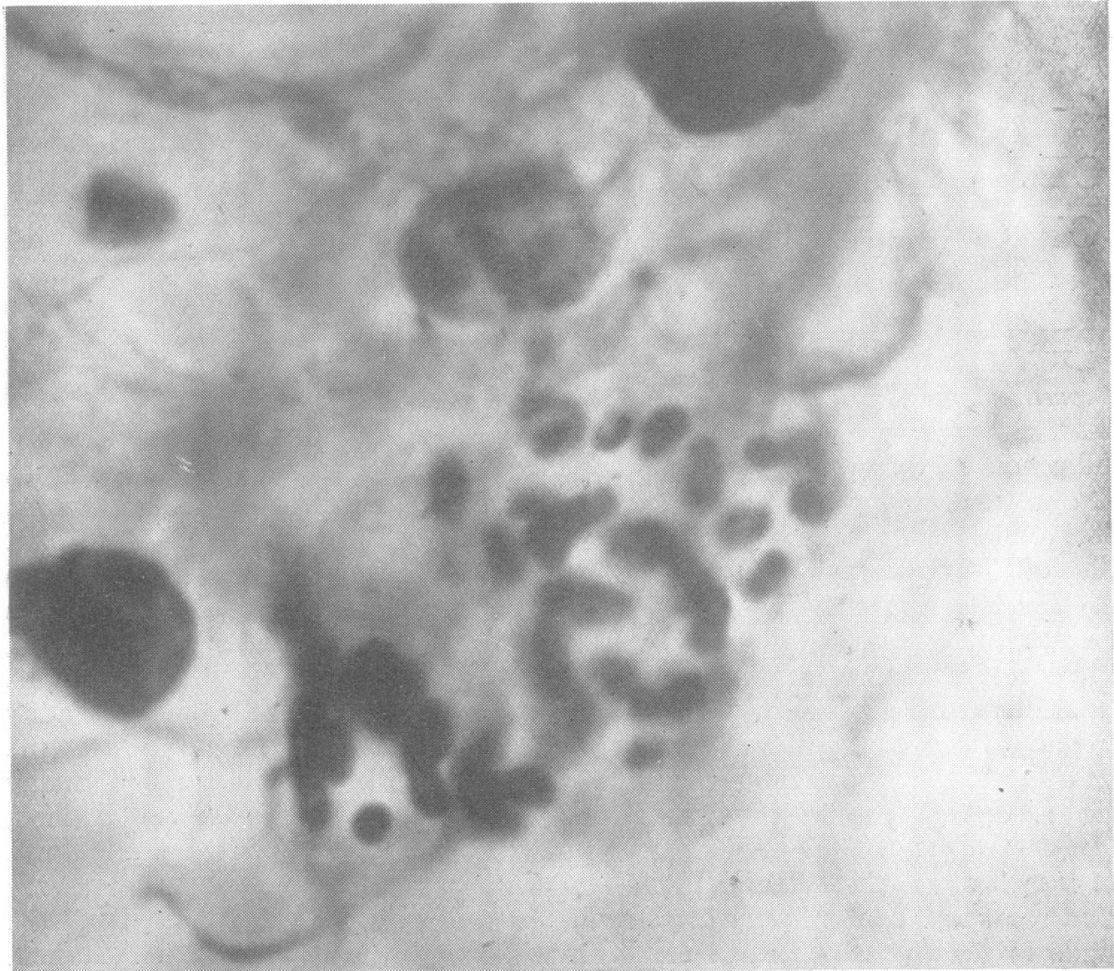

FIG. 2.-Biopsy section stained with Dieterle's silver technique demonstrating the closed safety-pin-like Donovan bodies (from Pund and Greenblatt, 1937b).

closed safety-pin appearance which is due to their elongated ovoid capsules and intense bipolar staining reaction (Fig. 2).

Tissue Smears.-The diagnosis may frequently be made without biopsy by examination of a smear from the lesion carefully obtained and stained. Many of the usual laboratory stains may be used. Wright's and Giemsa stains are quite satisfactory, and another simple and quick staining technique which may be used with advantage was recently described by Greenblatt and others (1951a). Using 1 per cent. pinacyanole in methyl alcohol to flood the slide for $1 \frac{1}{2}$ to 2 minutes, followed by the addition of an equal amount of neutral distilled water for the same length of time, the slide may be rinsed and examined under the high dry or oil immersion lens immediately after drying. The capsules of the Donovan bodies stain a lavender-pink and the nuclei a dark blue. This differential colour response facilitates recognition of the intracellular organisms. If isolated extracellular bodies, or occasionally cells containing large multilocular structures believed to be the immature encysted stage, are found, continued search of the slide will always reveal the large mononuclear cell containing intracytoplasmic Donovan bodies pathognomonic of the disease. When

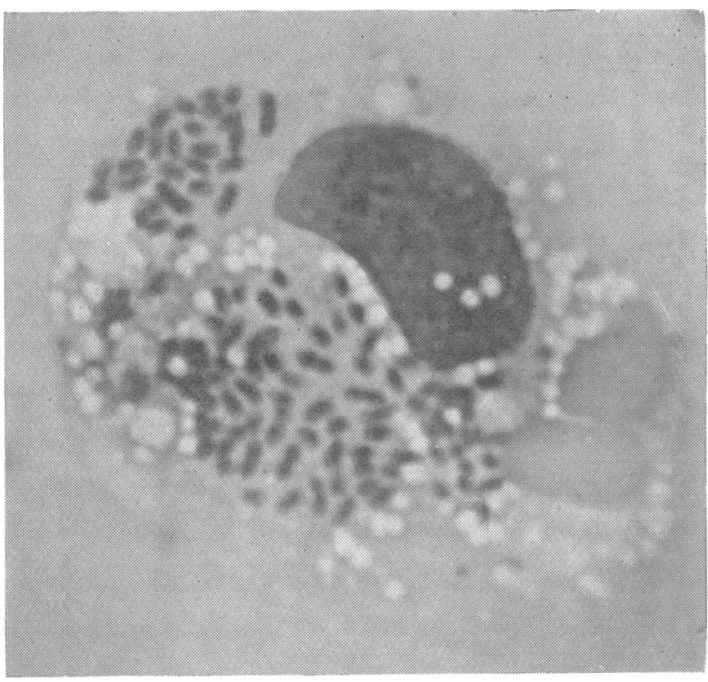

Fig. 3.-Pathognomonic large mononuclear cell with intracytoplasmic Donovan bodies. (Tissue smear.)

there is doubt, one should keep searching, for when once seen and recognized the organisms are sufficiently definite and characteristic to eliminate confusion with debris and other bacteria (Fig. 3). 


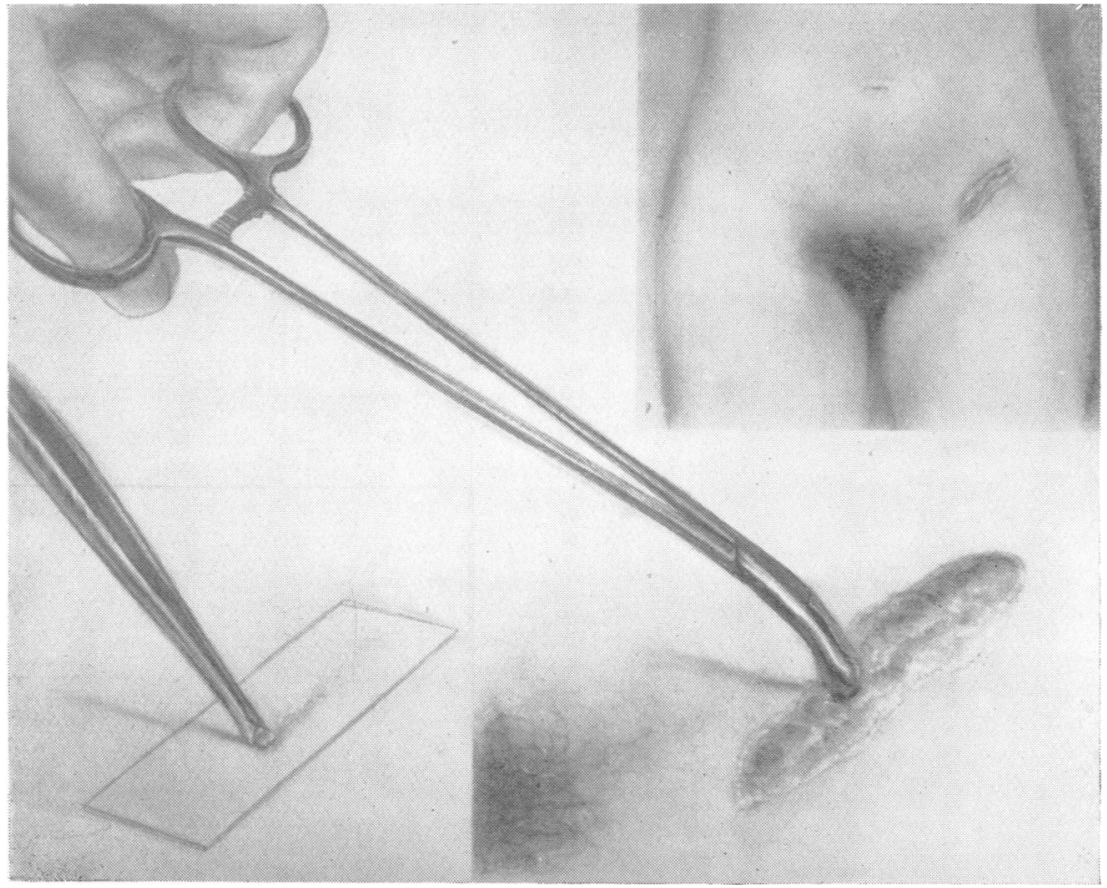

FIG.4.-Technique for obtaining good smears.

Method of obtaining Good Smears.-Much waste of time in searching for Donovan bodies may be avoided if special precautions are taken in obtaining the tissue smear. To prepare a slide from the surface of the lesion is often a waste of time because the surface smear usually contains such an abundance of fibrinous and purulent exudate with extensive secondary bacterial and fusospirochaetal infection that Donovan bodies are difficult to demonstrate. Better films are obtained by securing a small piece of clean granulation tissue from the lesion with the aid of a punch biopsy forceps, and then smearing the clean undersurface of the tissue along the glass slide, thus obtaining the deeper tissue fluids which contain a greater number of mature bodies and none of the purulent exudate (Fig. 4). The slide is allowed to dry in air, and is then "fixed" for 30 seconds by brief exposures to an open flame before staining.

Conventional teaching has perpetuated the fallacy that granuloma inguinale does not involve the lymphatic structures. It is true that granuloma inguinale is not primarily a disease of the lymphatics, but very often inguinal swelling and induration precede inguinal ulceration. The demonstration of the pathognomonic cells of granuloma inguinale in regional lymph nodes showing mild focal reactions and endothelial proliferation with perilymphadenitis at least indicates that the lymphatics have played a part in disseminating the disease. The inguinal ulceration, however, involves only the skin and subcutaneous tissues, and is not due to suppuration of the lymph nodes which is seen in the bubo of chancroid and lymphogranuloma venereum.

The Pseudobubo.-Frequently the indurated subcutaneous inguinal swelling which follows a lesion of granuloma inguinale on the genitalia forms a suppurative abscess, which has been termed by our group the "pseudobubo". The appreciation of this concept of the pseudobubo is important, in that heretofore the presence of a fluctuant inguinal abscess was believed to occur only in such conditions as lymphogranuloma venereum, chancroid, and gonococcal and non-specific infections. The presence of a pseudobubo in granuloma inguinale was corroborated by the Duke University group working on granuloma inguinale (Carter and others, 1939). The material used in our skin-test studies was obtained when we first suggested the concept of the pseudobubo. On several occasions, on examining the pus obtained by sterile aspiration of a large, fluctuant, inguinal abscess, we found only Donovan bodies with no other bacterial contamination.

Antigenic Response to the Skin Test.-The skin test has now been sufficiently studied for us to evaluate its usefulness in diagnosis.

Pus Antigen.-When the otherwise uncontaminated pus from a pseudobubo of granuloma inguinale was attenuated and made into an antigen 
for skin-test purposes, many good reactions were obtained on granuloma patients, but the over-all results were indecisive (Greenblatt, 1939).

The antigen used by Kornblith (1944) was prepared from the superficial tissue of an acute lesion of granuloma inguinale. He tested nineteen proved cases of the disease and a series of controls. All but two of the proved cases had a positive reaction, and all but two of the controls were negative.

Vaccine from in vitro Cultures.-Anderson and others (1945) successfully cultured the organism and prepared antigens from infected embryonic yolk cultures for skin testing. A suspension of inactivated Donovania granulomatis gave a positive skin test in all six patients tested by them for granuloma inguinale ; the filtered mucinous material from the culture ("capsular antigen") elicited a milder reaction on four granuloma patients; all nine controls were negative.

Since the antigenic properties of this disease had been relatively unexplored, Dr. Dienst of the Department of Bacteriology of the Medical College of Georgia prepared a vaccine from pure cultures of Donovan bodies obtained from a pseudobubo and grown in vitro on fresh egg yolk medium (Dienst and others, 1948). This vaccine from Donovania granulomatis was tested by Chen and others (1949). Observing the uniform criteria used in the Ducrey and Frei skin-test reactions (induration of $7 \mathrm{~mm}$. or more after 72 hours), all forty granuloma patients tested had a positive reaction, and a negative reaction to the yolk control. Among the nongranuloma control subjects, there were seven false positive reactions : two syphilitic, two tuberculous, one chancroid, one lymphogranuloma, and one hypogonad. Five other patients (four tuberculous and one chancroid) gave positive reactions to both the antigen and the yolk control, so these could not be interpreted as false positives. It was concluded from these observations that although a positive skin test does not confirm the diagnosis, a negative skin reaction may rule out granuloma inguinale in the study of a patient with some chronic ulcerating lesion. Furthermore, it was observed that skin reaction to the antigen begins as early as 2 weeks after the appearance of the lesion and persists indefinitely, since all four "cured" granuloma patients tested gave positive results.

Pathogenicity of Donovania granulomatis.Experimental reproduction of granuloma inguinale in man was first reported by McIntosh (1926) by subcutaneous implantation of diseased tissue in another patient. Our group first reported a typical lesion produced in volunteers by inoculation of exudate rich in Donovan bodies and free from other bacteria, obtained from a pseudobubo (Dienst and others, 1938 ; Greenblatt and others, 1939). This work was corroborated by Carter and others (1939). From these observations the aetiological significance of Donovan bodies in granuloma inguinale was apparently established. On the other hand, we were unable to produce this disease in animals or volunteers with pure in-vitro cultures of Donovania granulomatis (Dienst and others, 1949). Since it is believed that the fresh yolk agar cultured forms of Donovania granulomatis are identical with the intracytoplasmic Donovan bodies seen in tissue smears, it may be asked whether some other agent associated with the Donovan body is necessary to reproduce the disease.

\section{Therapy}

Antimonial Compounds.-Fuadin, anthiomaline, diramin, and tartar emetic were used for many years in the therapy of granuloma inguinale with only moderate success. The treatment schedule was long, recalcitrant cases were frequently encountered, and relapses occurred in more than half the patients.

Antibiotics.-Throughout our studies with the various antibiotics attempts have been made to determine optimal dosage schedules in order to obtain a standard basis for evaluation. Many lesions continued to heal after cessation of therapy; in others, the organisms reappeared, indicating that the arbitrary dosage was inadequate. When an optimal schedule was established for each of the drugs this was considered " a course of therapy". On this basis, when patients with extensive lesions required more than one course of therapy to obtain continued progress, or because of the reappearance of organisms after cessation of therapy, they were by no means considered as failures, but were retreated with the same drug for a long enough period to determine definite sensitivity or resistance to that drug before the therapy was changed (Tables I and II, opposite).

Streptomycin was the first antibiotic to offer hope for cure of the patient with granuloma inguinale. In our series of 142 patients (Kupperman and others, 1948 ; Greenblatt and others, 1950, 1952), fourteen required re-treatment, and 107 were healed at the end of therapy or on follow-up examinations, which varied in length from 2 to 18 months, 27 patients failed to return for follow-up examinations, and there were eight known failures. The average total. 
TABLE I

ANTIBIOTICS IN TREATMENT OF GRANULOMA INGUINALE

\begin{tabular}{|c|c|c|c|c|c|c|c|c|c|}
\hline Drug & & Route & $\begin{array}{c}\text { No. } \\
\text { of } \\
\text { Patients }\end{array}$ & $\begin{array}{l}\text { Average } \\
\text { Dose } \\
\text { (g.) }\end{array}$ & Retreatment & $\begin{array}{l}\text { Healed at End of } \mathbf{R x} \\
\text { or on Follow-up or } \\
\text { after Retreatment }\end{array}$ & $\begin{array}{l}\text { No } \\
\text { Follow- } \\
\text { up }\end{array}$ & Failures & $\begin{array}{l}\text { Range of } \\
\text { Dosage } \\
\text { (g.) }\end{array}$ \\
\hline Streptomycin & . & Intramuscular & 142 & 23.96 & 14 & 107 & 27 & 8 & 4.5 to 158.0 \\
\hline Aureomycin & $\ldots$ & Oral & 71 & $35 \cdot 55$ & 11 & 66 & 5 & none & $10 \cdot 8$ to $200 \cdot 0$ \\
\hline Chloromycetin & $\ldots$ & Oral & 46 & $36 \cdot 19$ & 10 & 41 & 4 & 1 & 20.0 to 145.0 \\
\hline Terramycin & $\ldots$ & Oral & 36 & $31 \cdot 62$ & 2 & 27 & 9 & none & 20.0 to 87.5 \\
\hline
\end{tabular}

TABLE II

DURATION OF FOLLOW--UP AFTER RX

\begin{tabular}{|c|c|c|c|c|c|c|c|c|c|c|c|c|c|}
\hline \multirow{3}{*}{\multicolumn{2}{|c|}{ Antibiotic }} & & \multirow{3}{*}{$\begin{array}{l}\text { Patients healed } \\
\text { at End of } \mathrm{Rx} \text { with } \\
\text { no Follow-up }\end{array}$} & \multicolumn{9}{|c|}{ Follow-up } & \multirow{3}{*}{ Total* } \\
\hline & & & & \multicolumn{8}{|c|}{ Months after Therapy } & \multirow{2}{*}{ None } & \\
\hline & & & & $0-2$ & $3-4$ & $5-6$ & $7-8$ & $9-10$ & $11-12$ & $13-15$ & $16-18$ & & \\
\hline Aureomycin & $\cdots$ & $\cdots$ & 1 & 16 & 8 & 6 & 7 & 4 & 17 & 5 & 1 & 6 & 71 \\
\hline Chloromycetir & & . & 3 & 8 & 9 & 5 & 10 & 2 & 2 & 2 & - & 4 & 45 \\
\hline Terramycin & $\cdots$ & $\cdots$ & 9 & 9 & 2 & 2 & 2 & 2 & 1 & 一 & 一 & 9 & 36 \\
\hline Streptomycin & $\ldots$ & $\ldots$ & 6 & 19 & 17 & 8 & 15 & 10 & 11 & 11 & 10 & 27 & 134 \\
\hline
\end{tabular}

* 295 patients treated ; 286 healed and 9 therapeutic failures not listed.

dose per patient was 23.96 g., and the optimal dosage was found to be $4.0 \mathrm{~g}$. daily for 5 days.

Aureomycin produced satisfactory healing in all 71 patients treated by oral therapy (Greenblatt and others, 1952; Wammock and others, 1950). Eleven required re-treatment. Five of the eight streptomycin-resistant cases were treated with aureomycin and all healed after adequate therapy (Greenblatt and others, 1948). One chloromycetinresistant patient also responded to aureomycin. Five patients failed to return for follow-up examination, but had healed, or were in the process of healing when dismissed. As far as we know, there were no failures. The optimal dosage was found to be $2.0 \mathrm{~g}$. daily for 10 to 20 days, and the average total dose per patient was $35.55 \mathrm{~g}$. Follow-up examinations were continued from 1 to 18 months.

Chloromycetin was administered orally to 46 patients with granuloma inguinale (Greenblatt and others, 1950, 1952, 1949); 41 were healed at the end of treatment or on follow-up examination, and the one known failure responded satisfactorily to aureomycin. Re-treatment was required in ten patients, and four were not seen for follow-up examination. The optimal dosage paralleled that determined for aureomycin, the average total dose per patient being $36 \cdot 19 \mathrm{~g}$.

Terramycin was employed orally in the treatment of 36 cases, and there were no known therapeutic failures (Greenblatt and others, 1950, 1952, 1951b). Two patients who required re-treatment responded satisfactorily to adequate therapy, and 27 of the 36 patients treated were healed at the conclusion of therapy or at the follow-up examinations which were continued for as long as 12 months, but nine patients failed to return for follow-up examinations. The average total dose per patient was $31.62 \mathrm{~g}$. with a dosage schedule of $2.0 \mathrm{~g}$. daily in divided doses.

\section{Summary}

(1) Satisfactory methods of diagnosis of granuloma inguinale employing specific techniques of histologic study and stained tissue smears, with suggestions for obtaining good smears, are discussed.

(2) A review and evaluation of the intradermal skin test in diagnosis of granuloma inguinale is presented.

(3) A review of the therapeutic results obtained in 295 patients with granuloma inguinale employing streptomycin, aureomycin, chloromycetin, or terramycin, is presented.

(4) Evidence of the possibility of eradicating this disease is offered on the basis of results obtained in the geographic area accessible to the Medical College of Georgia group of investigators.

(5) An analysis of the results obtained with the various antibiotics points to terramycin as the drug of choice, since patients so treated show fewer sidereactions, and a lower incidence of need for re- 
treatment, and require a smaller average total dose, than those receiving either of the other two oral antibiotics.

\section{REFERENCES}

Anderson, K., Goodpasture, E. W., and DeMonbreun, W. A. (1945). J. exp. Med., 81, 41.

Carter, B., Jones, C. P., and Thomas, W. L. (1939). J. infect. Dis., 64, 314.

Chen, C. H., Dienst, R. B., and Greenblatt, R. B. (1949). Amer. J. Syph., 33, 60.

Dienst, R. B., Chen, C. H., and Greenblatt, R. B. (1949). Ibid., 33,152 .

- Greenblatt, R. B., and Chen, C. H. (1948). Ibid., 32, 301.

,-- , and Sanderson, E. S. (1938). J. infect. Dis., 62, 112.

Greenblatt, R. B. (1939). Unpublished data.

- - Barfield, W. E., Dienst, R. B., and West, R. M. (1951b). J. ven. Dis. Inform., 32, 113.
Greenblatt, R. B., Barfield, W. E., Dienst, R. B., West, R. M., and Zises, M. (1952). Amer. J. Syph., 36, 186.

—, Dienst, R. B., Chen, C., and West, R. (1948). Sth. med. J., 41, 1121 .

$\longrightarrow,-$, Pund, E. R., and Torpin, R. (1939). J. Amer. med. Ass., 113, 1109.

-, , and West, R. M. (1951a). Amer. J. Syph., 35, 291.

_-, Wammock, V. S., Chen, C. H., Dienst, R. B., and West, R. M. (1950). J. ven. Dis. Inform., 31, 45.

,$- \frac{}{38}$, Dienst, R. B., and West, R. M. (1949). J. med. Ass. Ga., 38, 206.

Kornblith, B. A. (1944). N.Y. St. J. Med., 44, 2476.

Kupperman, H. S., Greenblatt, R. B., and Dienst, R. B. (1948) J. Amer. med. Ass., 136, 84.

McIntosh, J. A. (1926). Ibid., 87, 996

Pund, E. R., and Greenblatt, R. B. (1937a). Arch. Path., 23, 224. (1937b). J. Amer. med. Ass., 108, 1401.

Wammock, V. S., Greenblatt, R. B., Dienst, R. B., Chen, C., and West, R. M. (1950). J. invest. Derm., 14, 427. 